\title{
Comparison of Summer and Winter California Central Valley Aerosol Distributions from Lidar and MODIS Measurements
}

\author{
Jasper Lewis ${ }^{1}$, Russell De Young ${ }^{2}$, Richard Ferrare ${ }^{2}$, D. Allen $\mathrm{Chu}^{3}$ \\ ${ }^{1}$ Center for Atmospheric Science, Hampton University, Hampton, VA 23681 \\ ${ }^{2}$ Science Directorate, NASA Langley Research Center, Hampton, VA 23681 \\ ${ }^{3}$ Goddard Earth Science and Technology Center, University of Maryland Baltimore County, \\ Greenbelt, MD 20771
}

\begin{abstract}
Aerosol distributions from two aircraft lidar campaigns conducted in the California Central Valley are compared in order to identify seasonal variations. Aircraft lidar flights were conducted in June 2003 and February 2007. While the ground $\mathrm{PM}_{2.5}$ concentration is highest in the winter, the aerosol optical depth measured from MODIS is highest in the summer. A seasonal comparison shows that $\mathrm{PM}_{2.5}$ in the winter can exceed summer $\mathrm{PM}_{2.5}$ by $55 \%$, while summer AOD exceeds winter AOD by 43\%. Higher temperatures and wildfires in the summer produce elevated aerosol layers that are detected by satellite measurements, but not surface particulate matter monitors. Temperature inversions, especially during the winter, contribute to higher $\mathrm{PM}_{2.5}$ measurements at the surface. Measurements of the boundary layer height from lidar instruments provide valuable information need to understand the relationship between satellite measurements of optical depth and in-situ measurements of $\mathrm{PM}_{2.5}$.
\end{abstract}

\section{Introduction}

The California Central Valley is a major agricultural area stretching some $600 \mathrm{~km}$ from north to south and is one of the most productive agricultural regions in the world (Andrews et al., 2002). The southern half of the valley is known as the San Joaquin Valley encompassing nearly $64,000 \mathrm{~km}^{2}$. The valley has cool wet winters and hot dry summers. On the western edge of the valley is the Coastal Mountain range with peaks reaching 1,530 m. On the east side is the Sierra Nevada range (max 4,418 $\mathrm{m}$ ) and the Tehachapi Mountains $(\max 2,432 \mathrm{~m}$ ) form the southern 
boundary of the Valley, which contain mountain passes to the Los Angeles basin and the Mojave Desert. The surrounding mountains prevent ventilation of air masses, causing pollutants and their precursors to be retained in the valley. The valley topography and climate create ideal conditions for trapping and holding pollutants within the valley. The particle and gaseous emissions can recirculate within the valley and accumulate to unhealthy levels.

The valley is currently a nonattainment area with the $\mathrm{PM}_{2.5}$ National Ambient Air Quality Standard (NAAQS) because measurements of several monitoring sites exceed the annual $\mathrm{PM}_{2.5}$ standard, especially in the lower part of the valley (Geis, 2007) where air quality is a significant health issue. Significant progress has been made in reducing the $\mathrm{PM}_{10}$ and $\mathrm{PM}_{2.5}$ emissions and a plan is in place to meet the NAAQS and state standards for air quality in 2014 (SJV Air Pollution Control District, 2008a).

It should be noted however that valley emissions are not dominated by a single source. The observed $\mathrm{PM}_{2.5}$ levels represent aggregated urban emissions with contributions from the region. The local climate produces seasonal variations in particulate levels through the changes in atmospheric conditions that affect the types of emissions, emission rates, and atmospheric formation of particles from precursor emissions.

During fall and winter, meteorological conditions contribute to low wind speeds, lowlying inversion layers and increased secondary particle formation, all establishing a situation conducive to the formation and accumulation of $\mathrm{PM}_{2.5}$. Colder, frequently stagnant conditions occurring in December and January favor formation of ammonium nitrate, and thus experience the highest levels of ground $\mathrm{PM}_{2.5}$. The cold weather also induces the public to increase residential wood burning that further adds emissions to the atmosphere. During the winter, wind direction varies from the south-southeasterly directions to north-northwesterly directions. 
Temperature inversions trap aerosols below the mixing height, where they can remain more concentrated than when they can mix more freely with cleaner air at higher altitudes. This contributes to higher $\mathrm{PM}_{2.5}$ concentrations as inversions are formed more persistently (stable) during the winter months, when inversions occur from 15 to 300 meters.

In the summer, long periods of little or no rainfall result in extreme dryness of soils along roadways, increasing emissions from traffic movement. Limited rainfall during the summer months reduces the frequency of events that clear emissions from the local area. At night, cooler drainage winds from the surrounding mountains prevent exit of the air at the southern end of the Valley, causing recirculation of pollutants in a counterclockwise pattern and returning polluted air to urban areas. Throughout the valley, some of the pollutants transported to higher altitudes from daytime heating return to the surface at night by drainage winds from the mountains. In the spring and summer $\mathrm{PM}_{2.5}$ tends to be lower with mostly motor vehicle emissions, secondary sulfate, and primary geological material from the fine particle fraction of airborne soil. Daytime temperature inversions during the summer are usually not encountered until 610 to 760 meters above the surface (SJV Air Pollution Control District, 2008b).

Figure 1 summarizes the seasonal trends and chemical components of $\mathrm{PM}_{2.5}$ near Bakersfield, California in the lower valley. Winter and spring months are heavily dominated by secondary ammonium nitrate with moderate contributions of secondary sulfate, motor vehicle emissions, primary geological material and direct emission of organic aerosols identified as biomass burning from wood combustion, wild fires or agricultural burning. In the summer, organic carbon and ammonium sulfate dominate the composition of $\mathrm{PM}_{2.5}$.

The primary transport route into the Valley is from the northwest in the vicinity of Stockton where transport is directed from Stockton to Bakersfield for all the months except 
January and February. During the summer the air into the valley is directed from the northwest at all hours of the day. The primary transport route out of the valley is over the Tehachapi Mountains at the southeast of Bakersfield. This outflow pattern contributes significantly to the pollution in the Mojave Desert. The flow over the Tehachapi Mountains is most effective during the summer and nearly absent during winter periods because of stagnation. Upslope flow occurring during the afternoon throughout the year is effective in removing pollutants from foothills of the valley. A portion of the pollutants; however, is returned to the valley by the nocturnal drainage winds. Ventilation of the valley during the summer leads to a typical pollution residence time of 1-2 days, dependent upon location. During the winter, because of stagnation, typical residence times of 2-8 days may be experienced. In general, the air at ground level is warmed by sunlight causing it to rise and carry emissions aloft. This rising air pattern mixes the fresh emissions with air at higher elevations, dispersing the emissions and reducing the concentration of directly emitted $\mathrm{PM}_{2.5}$ and precursors. However, temperature inversion layers frequently block the rising air recirculating it down to the surface. (Smith et al., 1981).

This paper will compare the results of two airborne aerosol lidar campaigns over the San Joaquin Valley. The first campaign occurred in June 2003 (De Young et al., 2005) and the second in February 2007 (Al-Saadi et al., 2008). These two lidar campaigns provide contrasted aerosol conditions in summer and winter. The lidar returns will be used to derive aerosol optical depth (AOD) and compared with the MODIS (Moderate Resolution Imaging Spectroradiometer) AOD from the Terra and Aqua satellites. The advantage of aerosol lidar is that it provides the high-resolution vertical distribution of aerosols. Though it does not provide direct measurements of the number density of aerosols, it does measure the boundary layer height accurately, which is important since most of the $\mathrm{PM}_{2.5}$ aerosols observed during these lidar campaigns were confined 
within boundary layer. Lidar can also be used to determine the height of aerosol plumes above the boundary layer; these plumes can be transported from great distances. Lidar with multiple wavelengths and depolarization can be used to classify aerosol types (Sasano and Browell, 1989). While lidar gives high vertical resolution, but low spatial coverage, satellite AOD measurements give a very broad coverage, but columnar measurement at moderate resolutions. The synthesized lidar and satellite measurements can result in a better understanding of aerosols with ground $\mathrm{PM}_{2.5}$ concentrations for health and regulatory needs over a large area. This paper will examine lidar and MODIS AOD measurements in correlating ground $\mathrm{PM}_{2.5}$ concentrations with back trajectories in aid of tracking origins of air mass to give a clearer picture of the distribution of aerosols within the valley.

Publications describing aircraft lidar flights in the valley are rare. The first such campaign occurred in September 1994 when a 1064-nm lidar was flown along the California coast as validation for the Lidar In-Space Technology Experiment (LITE) (Strawbridge and Hoff, 1996). Pronounced aerosol structures were seen towards the southern end of the San Joaquin Valley, near Bakersfield.

\section{Experimental Configuration}

Two different aircraft lidar systems were used in this study. The 2003 lidar measurements were made using the Compact Aerosol Lidar (CAL) deployed on the NASA DC-8 during the DC-8 Inlet/Instrument Characterization Experiment (DICE), while the 2007 lidar measurements were made using the Airborne High Spectral Resolution Lidar (HSRL) deployed on the NASA King Air B-200. A summary of the two lidar systems is shown in Table 1.

\subsection{Compact Aerosol Lidar (CAL)}


The CAL used in the 2003 San Joaquin Valley campaign was built in the Science Directorate of NASA Langley Research Center (DeYoung, 2005; Gili and DeYoung, 2006). The standard backscatter lidar system, depicted in Figure 2, has dimensions of 108-cm x 64-cm x 53$\mathrm{cm}$ and a mass of $115-\mathrm{kg}$ and was flown on the NASA DC-8. The laser is a frequency doubled Nd:YAG (Big Sky Laser - Quantel) with a 20-Hz repetition rate. The 1064-nm and 532-nm energies are typically $60-\mathrm{mJ}$ and $80-\mathrm{mJ}$, respectively. A steerable $45^{\circ}$ turning mirror is used to align the transmitted beam to the telescope. The atmospheric return passes to the receiver box by a 1-mm diameter optical fiber coupled to the focal point of a 0.30 -m diameter telescope.

The received light is collimated and split into 1064-nm and 532-nm channels, with a further split of the 532-nm wavelength into analog (90\%) and photon counting (10\%) channels. The 1064-nm return passes through a 1-nm full-width-at-half-maximum (FWHM) filter before being focused onto an avalanche photodiode (APD) detector. The 532-nm return passes through a 0.5 -nm FWHM filter before being split between analog and photon-counting photomultiplier detectors. Data are averaged over a 2-s (40 shots) time interval before being stored by the computer.

\subsection{Airborne High Spectral Resolution Lidar (HSRL)}

The Airborne HSRL used in the 2007 San Joaquin Valley campaign was also developed in the Science Directorate of NASA Langley Research Center (Hair et al., 2008) and deployed on the NASA King Air B-200. The HSRL takes advantage of Doppler broadening to independently resolve the molecular and aerosol atmospheric lidar returns. Backscattered radiation from air molecules is Doppler broadened on the order of $\mathrm{GHz}$ due to the high-velocity random thermal motion of the molecules. By contrast, slower-velocity aerosol particles are only Doppler broadened on the order of $\mathrm{MHz}$ due to their much larger mass. An extremely narrow- 
band iodine vapor $\left(\mathrm{I}_{2}\right)$ absorption filter is used to separate the molecular return from the aerosol return at the 532-nm wavelength. The HSRL instrument also functions as a standard backscatter lidar at the 1064-nm wavelength.

The HSRL system depicted in Figure 2, uses a 200-Hz pulsed Nd:YAG laser (Fibertek). The 1064-nm and 532-nm energies are 1.1-mJ and 2.5-mJ, respectively. The receiver employs a 40-cm telescope with a 1-mrad field of view. The transmitter and receiver occupy a volume with dimensions of $83-\mathrm{cm} \times 56-\mathrm{cm} \times 76-\mathrm{cm}$, while the data acquisition and control system occupies an additional $0.37-\mathrm{m}^{3}$.

The 1064-nm lidar return passes through a 0.4-nm FWHM interference filter before being separated into parallel and perpendicular polarization channels, which distinguishes between spherical and nonspherical particles. The 532-nm lidar return passes through a temperature tuned, 60-pm etalon, (Coronado), and then splits between the boresight detector (4\%) which maintains alignment between the transmitter and receiver, the parallel and perpendicular polarization channels $(10 \%)$, and the $I_{2}$ filter and molecular return channel (86\%). Data are typically averaged over a 0.5 -s (100 shots) time interval before being stored by the computer.

A more complete description of the HSRL system and the methods used to retrieve aerosol parameters from this system is described by Hair et al. (2008). Rogers et al. (2009) compared the HSRL layer AOD values to AOD derived from the airborne Sun photometer with the results showing HSRL lower by a bias difference of $-0.0032(-6.5 \%)$ and an rms difference of $0.0079(15.6 \%)$. They also compared the HSRL AOD values with coincident AOD measured by AERONET (Holben et al., 2001) ground-based sun photometers and found the HSRL optical depth lower by a bias difference of -0.015 or $-6 \%$.

\subsection{Moderate Resolution Imaging Spectroradiometer (MODIS)}


MODIS is a 36-channel spectroradiometer onboard both Terra and Aqua satellites of the Earth Observing Systems (EOS). The MODIS spectral channels used in retrieving aerosol optical depth (AOD) over land and ocean include two 250-m (660 and 860-nm channels), and five 500$\mathrm{m}(470,550,1240,1640$, and 2130-nm) channels. The 250-m resolution $660 \mathrm{~nm}$ and $860 \mathrm{~nm}$ channels are used to detect water bodies such as lakes or rivers. Then the aggregated 500-m resolution $660-\mathrm{nm}$ and $860-\mathrm{nm}$ reflectances together with other 500-m channels are used to derive aerosol optical depths. The detailed methodology of the MODIS aerosol algorithm for the procedures of screening clouds and surface snow/ice was described by Remer et al. (2006). At the final step, pixels that pass screenings are further analyzed for AOD retrieval. For example, in a $10 \mathrm{~km}$ grid, pixels are further selected by removing the upper $50 \%$ and the lower $20 \%$ of the pixels to avoid possible sub-pixel contamination by clouds, surface snow/ice, and water bodies. The algorithm requires the final number of pixels to be greater than 12 to have a valid retrieval. Otherwise, the algorithm reports a missing AOD retrieval. Over vegetated and semi-arid surfaces where AOD values are shown as the majority of MODIS retrievals, the AOD products have been widely used in routine air quality monitoring, such as Infusing satellite Data into Environmental Applications (IDEA) (http://idea.umbc.edu) (Al-Saddi et al, 2005) and in correlating with surface $\mathrm{PM}_{2.5}$ concentrations for public health related studies (Kumar et al., 2007; Kumar et al., 2008)

MODIS 5x5-km AOD products are derived based upon the operational 10x10-km algorithm (Level 2, Collection 005) with 100 available pixels. Thus the degree of freedom in selecting the best pixels is largely reduced. To maintain the quality of retrieval at the same level as the operational $10 \times 10-\mathrm{km}$ retrievals, we choose to use the same requirement of minimum number of pixels -12 pixels for the $5 \times 5-\mathrm{km}$ retrievals. Though the number of available pixels is significantly reduced (by a factor of 4 from $10 \mathrm{~km}$ to $5 \mathrm{~km}$ ), the quality of the retrieval, however, 
is retained, which is important for the case studies with variable clouds above the California Central Valley. Note that the 5x5-km AOD retrievals are derived only over land for comparisons with 10x10-km AOD values in correlating with $\mathrm{PM}_{2.5}$ ground measurements.

\section{Results}

The data used for comparison between the summer and winter San Joaquin Valley campaigns were collected on the dates of June 3, 5, 11, 12, and 17 of 2003 using the CAL, and the dates of February 15, 16, and 17 of 2007 using the Airborne HSRL. For each campaign, comparisons of the lidar derived AOD (532-nm) to MODIS AOD (550-nm), AERONET AOD (500-nm), wind back trajectories, $\mathrm{PM}_{2.5}$ and $\mathrm{PM}_{10}$ mass concentrations, and lidar extinction profiles (1064-nm) will be presented.

While the winter 2007 lidar flights were designed to fly over $\mathrm{PM}_{2.5}$ stations stretching from the northern to the southern end of the San Joaquin Valley, the summer 2003 lidar flights were mainly focused on the southern part of the valley. Since both campaigns conducted flights over Bakersfield, special attention will be given to the Bakersfield area data.

\subsection{Summer 2003 Campaign}

The 532-nm wavelength was unavailable during this campaign; therefore, the lidar derived AOD was obtained by converting the 1064-nm AOD to a 532-nm AOD using the Angstrom exponent. In this calculation, it was assumed that the Angstrom exponent for the 500nm and 1020-nm AERONET wavelengths measured from Fresno, CA could be used for the 532$\mathrm{nm}$ and 1064-nm lidar wavelengths with negligible error. The power returned to the lidar receiver, $P(\mathrm{z})$, is given by the lidar equation as:

$$
P(z)=\frac{C}{z^{2}}\left[\beta_{m}(z)+\beta_{a}(z)\right] T^{2}(z)
$$


where $C$ is the calibration constant, $\beta_{\mathrm{m}}(z)$ is the molecular backscattering coefficient, $\beta_{\mathrm{a}}(z)$ is the aerosol backscattering coefficient, and $T(z)$ is the one-way transmittance from the lidar to the height $z$. The lidar data is inverted using the Fernald method (Fernald et al., 1972; Fernald, 1984) to determine the aerosol backscatter coefficient, $\beta_{\mathrm{a}}$. The lidar AOD, $\tau$, is calculated as:

$$
\tau=S_{a} \int_{0}^{z^{*}} \beta_{a}(z) d z
$$

where $S_{a}$ is the lidar ratio and $\mathrm{Z}^{*}$ is an altitude where it is assumed only molecular scattering occurs (i.e. $\left.\beta_{\mathrm{a}}\left(Z^{*}\right)=0\right)$.

For two different wavelengths $\lambda_{1064}$ and $\lambda_{532}$ the Angstrom exponent, $\gamma$, relates the optical thicknesses $\tau_{1064}$ and $\tau_{532}$ such that:

$$
\tau_{532}=\tau_{1064}\left(\frac{\lambda_{532}}{\lambda_{1064}}\right)^{-\gamma}
$$

Optical depths calculated using Eq. (3) are referred to as the converted 532-nm AOD in the sections that follow. A similar calculation was performed to determine the converted 532-nm aerosol extinction for the 2003 lidar campaign. The 1064-nm lidar ratio used to invert the lidar signal was selected by matching the converted 532-nm AOD to the MODIS AOD along a small segment of the lidar flight path (usually averaged over 2-3 MODIS pixels near Bakersfield).

Figure 3 shows the summer 2003 comparison of Aqua satellite MODIS AOD at 550-nm with $5 \times 5-\mathrm{km}$ resolution to the lidar derived AOD from CAL for each flight date. High optical depths (> 0.3) are measured by MODIS throughout the San Joaquin Valley, as well as, near San Francisco and Los Angeles. Moving south from Stockton to Bakersfield, there appears to be an increase in aerosol loading. Table 2 provides a summary of each individual flight. The 
Angstrom exponents were calculated using Eq. (3) and the 1020-nm and 500-nm optical depths from the AERONET site in Fresno, CA. The lidar ratios and Angstrom exponents are in the range of what is expected for urban/industrial aerosols (Ackermann 1998; Mattis et al. 2004).

Figure 4 shows the 24-hr air mass back trajectories at Stockton, Fresno, and Bakersfield for 60-m and 2000-m altitudes calculated using the HYSPLIT model (available at http://www.arl.noaa.gov) along with ground particulate matter concentrations throughout the San Joaquin Valley at the time of the MODIS overpass. The majority of the trajectories indicate transport is contained within the valley or from the western part of California, with the exception of June 5 the June 17, which shows influence from eastern California/Nevada at an altitude of 2km. Despite the high values of MODIS AOD, the $\mathrm{PM}_{2.5}$ ground concentrations are relatively low for the region. Using the values from the Stockton, CA ground monitor, $\mathrm{PM}_{2.5}$ makes up $20 \%-25 \%$ of the $\mathrm{PM}_{10}$ mass concentration.

Figure 5 shows curtain plots of the converted 532-nm aerosol extinction for each of the flight dates. The highest extinction values are measured near Bakersfield and the Tehachapi Mountains, as shown in the figures. The planetary boundary layer height for the region is between 1.5 and $2-\mathrm{km}$. In the majority of the curtain plots, the peak in aerosol extinction is well above the surface, which may explain why the ground $\mathrm{PM}_{2.5}$ mass concentrations do not measure the high level of aerosol loading that is measured by the MODIS instrument.

The nearest MODIS pixel within \pm 0.1 degrees latitude/longitude for each lidar flight track was determined in order to compare the optical depths from MODIS to the lidar-derived AOD from CAL. Figure 6 shows the comparisons at 10x10-km (R-squared $=0.311)$ and $5 \times 5-\mathrm{km}$ $(\mathrm{R}$-squared $=0.396)$ resolutions.

\subsection{Winter 2007 Campaign}


The Airborne HSRL AOD was obtained directly via the HSRL technique from the 532nm wavelength lidar channel as described by Hair et al. (2008). Figure 7 shows the comparison between the lidar derived AOD and MODIS during the winter 2007 San Joaquin Valley campaign. Because both Aqua and Terra satellite overpasses occurred during the February 15 lidar flight, the lidar flight path is shown compared to both satellite MODIS AOD values. Similar to the summer 2003 campaign, the highest AOD are located in the central part of the Valley and near San Francisco and Los Angeles; however, the AOD values are lower than those measured during the 2003 summer. Table 3 provides a summary of each of the aircraft lidar flights. The standard deviations shown for the Angstrom exponent and 532-nm lidar ratio relate to the variability in the vertical profile of the two quantities. The Angstrom exponents were calculated using Eq. (3) and the 532-nm and 1064-nm extinction within the PBL determined from HSRL, since AERONET data from Fresno was unavailable during this lidar campaign. The 532-nm lidar ratio is a direct measurement from the HSRL lidar system, unlike the CAL data, which require information from independent sources.

Figure 8 shows the 24-hr back trajectories from Stockton, Fresno, and Bakersfield at 60$\mathrm{m}$ and 2000-m altitudes with $\mathrm{PM}_{2.5}$ mass concentrations measured at the time of the lidar flight, during the 2007 campaign. Again, aerosol transport appears to be mostly contained within the valley, with air masses moving from north to south. One exception is on February 17, when surface-level winds originate from the east. Even though the measurements of optical depth are lower than those measured in 2003, the $\mathrm{PM}_{2.5}$ mass concentration in 2007 is nearly doubled compared to that of the summer campaign. Using the values obtained from the Fresno ground monitor, $\mathrm{PM}_{2.5}$ makes up $56 \%-83 \%$ of the $\mathrm{PM}_{10}$ mass concentration. 
Figure 9 shows the curtain plots of the 532-nm aerosol extinction for each aircraft lidar flight. The planetary boundary layer is shallower than during the 2003 campaign, between approximately $1-\mathrm{km}$. The shallow boundary layer heights are believed to contribute to the increase in the ground $\mathrm{PM}_{2.5}$ mass concentration. Aerosol particles that were trapped near the surface allowed more particulate matter to be measured than in the case of elevated aerosols in the summer of 2003.

The nearest MODIS pixel within \pm 0.1 degrees latitude/longitude of the lidar flight track was used to compare the MODIS and HSRL AOD. Figure 10 shows that the R-squared correlation improves as the spatial resolution of MODIS increases from 10x10-km (0.539) to 5x5-km (0.696). The correlation improves even further (0.797) when the MODIS scattering angle is limited to values greater than 130 degrees. MODIS tends to overestimate the AOD when compared to HSRL, which matches the behavior from previous studies in the western United States (Prados et al., 2007).

\subsection{Bakersfield, CA Comparison}

Bakersfield, CA, located in the southern end of the San Joaquin Valley, is the only city in flight range of both aircraft campaigns. Table 4 displays the lidar-derived AOD, planetary boundary layer (PBL) height, and $\mathrm{PM}_{2.5}$ mass concentration measured during the closest aircraft lidar overpass for each campaign day and Table 5 shows the ratio of AOD to PBL height and the product of $\mathrm{PM}_{2.5}$ mass concentration and PBL height. The ratio of total column AOD to the PBL height is nearly the same for both the winter and summer campaigns. Similarly, the product of the $\mathrm{PM}_{2.5}$ mass concentration and PBL heights is nearly the same for both campaigns, which suggests an inverse relationship between the two. 
Figure 11 shows the mean 532-nm aerosol extinction profile near Bakersfield for the entire 2003 summer campaign compared with a similar profile from the 2007 winter campaign. As previously mentioned, the PBL height is much higher in the summer than in the winter. Also note the elevated peak in aerosol extinction during the summer campaign; whereas, aerosol extinction peaks near the surface during the winter.

\subsection{Seasonal AOD-PM 2.5 Comparisons}

The 10x10-km operational MODIS AOD (Level 2, Collection 005) from Aqua was used to determine the mean AOD in the San Joaquin Valley for the months of February (winter) and June (summer) during the years between 2003 and 2008. Dates when cloud cover prevented AOD retrievals were removed from the comparison resulting in a total of 103 retrievals in winter and 174 retrievals in summer. Table 6 shows the comparison of the mean AOD within the San Joaquin Valley for each year. With the exception of 2007, the summer AOD is higher than the winter AOD. The largest percent difference between the summer and winter AOD occurred in 2008 as a result of wildfires from the Northern California Lightning Series (Thompson, 2008). Table 7 shows the comparison of $\mathrm{PM}_{2.5}$ measured in Bakersfield (5558 California Avenue site) in the months of February and June for the years between 2003 and 2008. In all cases, $\mathrm{PM}_{2.5}$ concentration is highest in the winter.

The seasonal trends of AOD and $\mathrm{PM}_{2.5}$ found from the satellite and surface data generally agree with the findings of the 2003 and 2007 aircraft lidar campaigns. While the $\mathrm{PM}_{2.5}$ mass concentration is always higher in the winter, the MODIS AOD is higher in the summer (with the exception of 2007). Over the six-year time period, the $\mathrm{PM}_{2.5}$ in winter is $55 \%$ higher than the summer $\mathrm{PM}_{2.5}$; however, the summer AOD is $43 \%$ higher than the winter AOD. 
A likely explanation for the difference is in the summer elevated aerosols due to higher PBL heights and aloft layers from wildfires add to the MODIS AOD, but are not completely measured by $\mathrm{PM}_{2.5}$ monitors on the surface. For example, Figure 12 shows smoke pollution from wildfires on June 23-25 during the 2008 Lightning Siege (California Dept. of Forestry and Fire Protection, 2008). In particular, the $\mathrm{PM}_{2.5}$ mass concentrations measured at Bakersfield on June $24\left(37 \mu \mathrm{g} \mathrm{m}^{-3}\right)$ and June $25\left(64 \mu \mathrm{g} \mathrm{m}^{-3}\right)$ are lower than expected from the MODIS AOD measurements of 0.77 and 1.72, respectively. In Figure 13, a CALIPSO overpass of the Central Valley on June 23 shows smoke layers aloft as high as 4-km, which cannot be measured by $\mathrm{PM}_{2.5}$ ground monitors. By contrast, in the winter, low inversion layers combined with wood burning result in high $\mathrm{PM}_{2.5}$ measurements, even at low AODs.

\subsection{Conclusions}

Aerosol distributions in the San Joaquin Valley, as measured by two different aircraft lidar systems and MODIS sensors onboard Terra and Aqua satellites, are compared for summer (June 2003) and winter (February 2007). MODIS AOD data are increasingly being used as an indication of ground air quality and in the San Joaquin Valley this is important as the Valley has significant air quality concerns. While satellite data give a broad area picture of the AOD, they do not give the vertical distribution of the aerosols, which is why lidar measurements are needed. These data must then be correlated with ground-based $\mathrm{PM}_{2.5}$ measurements to understand the air quality throughout the Valley.

MODIS AOD tended to be higher in the summer than in the winter campaign and highly non-uniform throughout the Valley. Generally AOD increased toward the lower Valley. The two lidar campaigns had different flight tracks, but they did overlap in the Bakersfield, CA area where the summer lidar campaign had an average AOD of 0.21 with a ground $\mathrm{PM}_{2.5}$ of $16.6 \mu \mathrm{g}$ 
$\mathrm{m}^{-3}$ and the winter lidar campaign had an average AOD of 0.15 with a ground $\mathrm{PM}_{2.5}$ of $29.3 \mu \mathrm{g}$ $\mathrm{m}^{-3}$. The corresponding average PBL heights were $1.54 \mathrm{~km}$ (summer) and $1.0 \mathrm{~km}$ (winter), showing a correlation between the reduced PBL height and increase in $\mathrm{PM}_{2.5}$ concentration during the winter.

While the $\mathrm{PM}_{2.5}$ sources are different in the summer and winter seasons, the PBL does seem to play a significant role in the $\mathrm{PM}_{2.5}$ as measured on the ground. If the PBL height and the associated $\mathrm{PM}_{2.5}$ mass concentration are multiplied together the summer value is $25.6 \mu \mathrm{g} \mathrm{m}^{-3} \mathrm{~km}$ and the winter value is $29.2 \mu \mathrm{g} \mathrm{m}^{-3} \mathrm{~km}$, nearly the same for the Bakersfield area. It would be interesting to determine if this value remains fairly constant throughout the year resulting in a straightforward way to determine $\mathrm{PM}_{2.5}$ by measuring local AOD. The summer lidar profiles consistently showed an increase in extinction above the ground making the use of MODIS AOD as an indicator of ground $\mathrm{PM}_{2.5}$ problematic.

A comparison of summer and winter MODIS AOD from 2003 to 2008 showed the AOD in the summer exceeded the winter AOD by $43 \%$. However, during the same time period, the winter $\mathrm{PM}_{2.5}$ mass concentration exceeded the summer $\mathrm{PM}_{2.5}$ mass concentration by an average of $55 \%$.

The increased use of ground-based aerosol lidars in the Valley could, along with the broader area MODIS AOD data, substantially improve the understanding of air quality. A network of lidar systems collocated with the current ground $\mathrm{PM}_{2.5}$ monitors should be implemented in the San Joaquin Valley in order to assess the role the PBL height plays in the seasonal variation in $\mathrm{PM}_{2.5}$ measurements. While measurements would be less frequent than with a permanent ground-based network, CALIPSO offers another method of monitoring vertical aerosol distributions in the San Joaquin Valley. 


\section{Acknowledgements}

The authors would like to thank James J. Szykman, Jassim A. Al-Saadi, Chris A. Hostetler, Johnathan W. Hair, Anthony L. Cook, and David B. Harper, for the planning, collection, and use of the 2007 San Joaquin Valley HSRL data. 


\section{REFERENCES}

Ackermann, J., (1998): The extinction-to-backscatter ratio of tropospheric aerosol: a numerical study. J. Atmos. Oceanic Technol., 15, 1043-1050.

Al-Saadi, J.A and Coauthors, (2005): Improving national air quality forecasts with satellite aerosol observations. Bull. Amer. Meteor. Soc., 86, 1249-1261.

Al-Saadi, J.A. and Coauthors (2008): Application of satellite aerosol optical depth and airborne lidar data for monitoring fine particulate formation and transport in San Joaquin Valley, California. Preprints, $10^{\text {th }}$ Conference on Atmospheric Chemistry, New Orleans, LA, Amer. Meteor. Soc.

Andrews, S.S. and Coauthors (2002): On-farm assessment of soil quality in California's Central Valley. Agron. J., 94, 12-23.

De Young, R.J., W.B. Grant, and K. Severance (2005): Aerosol Transport in the California Central Valley Observed by Airborne Lidar. Environ. Sci. Technol., 39, 83518357.

Fernald, F.G., (1984): Analysis of atmospheric lidar observations: Some comments. Appl. Opt., 23, 652-653.

Fernald, F.G., B.M. Herman, and A. Reagan, (1972): Determination of aerosol height distributions by lidar. Appl. Meteorol., 11, 482-489.

Geis, Sonya (2007, October 8): Smog traps California community. Washington Post, p. A03.

Gili, C. and R. De Young (2006): A compact efficient lidar receiver for measuring atmospheric aerosols. NASA Tech. Rep., NASA/TP-2006-213950, 19 pp.

Hair, J.W. and Coauthors (2008): Airborne high spectral resolution lidar for profiling 
aerosol optical properties. Appl. Opt., 47, 6734-6753.

Kumar, N., A. Chu, and A. Foster, (2007): An empirical relationship between $\mathrm{PM}_{2.5}$ and aerosol optical depth in Delhi Metropolitan. Atmos. Environ., 41, 4492-4503.

Kumar, N., A. Chu, and Andrew Foster, (2008): Remote sensing of ambient particles in Delhi and its environs: estimation and validation, Int. J. Remote Sens., 29 (12), 3383-3405.

Mattis, I., A. Ansmann, D. Müller, U. Wandinger, D. Althausen, (2004): Multiyear aerosol observations with dual-wavelength Raman lidar in the framework of EARLINET. $J$. Geophys. Res., 109, D13203, doi:10.1029/2004JD004600.

Remer, L.A. and Coauthors, (2006): Algorithm for remote sensing of tropospheric aerosol from land: collection 5. Retrieved August 25, 2009 from http://modis-atmos.gsfc.nasa.gov/reference_atbd, ATBD-MOD-96, NASA Goddard Space Flight Center.

Rogers, R. and Coauthors, (2009): NASA LaRC airborne high spectral resolution lidar aerosol measurements during MILAGRO: observations and validation. Atmos. Chem. Phys., 9, $4811-4826$.

Prados, A., S. Kondragunta, P. Ciren, and K. Knapp (2007): GOES Aerosol/Smoke Product (GASP) over North America: Comparisons to AERONET and MODIS observations. $J$. Geophys. Res, 12, D15201, doi: 10.1029/2006JD007968.

San Joaquin Valley Air Pollution Control District (2008a): Annual report to the community. Retrieved March 9, 2009 from http://www.valleyair.org/General_info/pubdocs/2008AnnualReportfinal-web.pdf San Joaquin Valley Air Pollution Control District (2008b): 2008 PM$_{2.5}$ Plan - Final 
Adopted April 30, 2008. Retrieved March 9, 2009 from

http://www.valleyair.org/air_quality_plans/AQ_Final_Adopted_PM25_2008.htm

Sasano, Y. and E.V. Browell (1989): Light scattering characteristics of various aerosol types derived from multiple wavelength lidar observations. Appl. Optics, 28 (9), 16701679.

Smith, T.B, D.E. Lehrman, D.D. Reible, and F.H. Shair (1981): A Study of the Origin and Fate of Air Pollutants in California's Sacramento Valley, Final Report to the California Air Resources Board, December 1981.

Strawbridge, K.B. and R.M. Hoff (1996): LITE validation experiments along California's coast: preliminary results. Geo. Res. Lett., 23, 73-76.

Thompson, D. (2008, June 28). Smoky skies threaten health in fiery California. Associated Press. Retrieved from http://www.foxnews.com/wires/2008Jun28/0,4670,Wildfires,00.html 
TABLE 1. Summary of lidar properties for CAL and Airborne HSRL lidars

\begin{tabular}{|c|c|c|}
\hline & CAL & HSRL \\
\hline \multicolumn{3}{|l|}{ Laser } \\
\hline Manufacturer & Big Sky (Quantel) & Fibertek \\
\hline Repetition rate & $20-\mathrm{Hz}$ & $200-\mathrm{Hz}$ \\
\hline Beam divergence & $1.5-\mathrm{mrad}$ & $0.8-\mathrm{mrad}$ \\
\hline 1064-nm energy & $60-\mathrm{mJ}$ & $1.1-\mathrm{mJ}$ \\
\hline 532-nm energy & 80-mJ & $2.5-\mathrm{mJ}$ \\
\hline \multicolumn{3}{|l|}{ Telescope } \\
\hline Diameter & $0.30-\mathrm{m}$ & $0.40-\mathrm{m}$ \\
\hline FOV & $1.6-\mathrm{mrad}$ & $1.0-\mathrm{mrad}$ \\
\hline \multicolumn{3}{|l|}{ Filters } \\
\hline 1064-nm & 1-nm, FWHM & 0.4-nm, FWHM \\
\hline $532-\mathrm{nm}$ & 0.5-nm, FWHM & 60-pm (etalon), FWHM \\
\hline \multicolumn{3}{|l|}{ Detectors } \\
\hline 1064-nm channel & APD (analog) & APD (analog) \\
\hline 532-nm channel & $\begin{array}{l}\text { PMT (analog \& photon } \\
\text { counting) }\end{array}$ & PMT (analog) \\
\hline
\end{tabular}


TABLE 2. Summary of summer 2003 San Joaquin Valley campaign.

\begin{tabular}{cccccc}
\hline \hline Date & Takeoff & MODIS Overpass & Altitude & Angstrom & 1064-lidar ratio \\
& (UTC/PST) & $($ UTC $)$ & $(\mathrm{km})$ & exponent & $(\mathrm{sr})$ \\
\hline June 3, 2003 & $23: 40 / 16: 40$ & Aqua 21:05 & 6 & 1.451 & 40 \\
June 5, 2003 & $22: 39 / 15: 39$ & Aqua 20:55 & 11 & 1.436 & 30 \\
June 5, 2003 & $27: 16 / 20: 16$ & Aqua 20:55 & 12 & 1.436 & 30 \\
June 11, 2003 & $27: 16 / 20: 16$ & Aqua 20:15, 20:20 & 12 & 1.060 & 35 \\
June 12, 2003 & $23: 33 / 16: 33$ & Aqua 21:00 & 12 & 1.151 & 30 \\
June 17, 2003 & $19: 55 / 12: 55$ & Aqua 21:20 & 6 & 1.377 & 30 \\
\hline
\end{tabular}


TABLE 3. Summary of winter 2007 San Joaquin Valley campaign.

\begin{tabular}{cccccc}
\hline Date & $\begin{array}{c}\text { Takeoff } \\
(\text { UTC/PDT })\end{array}$ & $\begin{array}{c}\text { MODIS Overpass } \\
(\text { UTC })\end{array}$ & $\begin{array}{c}\text { Altitude } \\
(\mathrm{km})\end{array}$ & $\begin{array}{c}\text { Angstrom } \\
\text { exponent }\end{array}$ & $\begin{array}{c}\text { 532-lidar ratio } \\
(\mathrm{sr})\end{array}$ \\
\hline Feb. 15, 2007 & $19: 58 / 11: 58$ & Terra 19:25 & 8.8 & $1.56 \pm 0.62$ & $47.7 \pm 5.5$ \\
& & Aqua 21:05 & & & \\
Feb. 16, 2007 & $15: 58 / 7: 58$ & Terra 18:30 & 8.9 & $1.81 \pm 0.46$ & $59.0 \pm 8.4$ \\
Feb. 16, 2007 & $20: 49 / 12: 49$ & Aqua 21:45 & 8.9 & $1.55 \pm 0.54$ & $46.7 \pm 5.6$ \\
Feb. 17, 2007 & $18: 10 / 10: 10$ & Terra 19:15 & 8.8 & $1.49 \pm 0.76$ & $42.7 \pm 4.8$ \\
Feb. 17, 2007 & $23: 53 / 15: 53$ & Aqua 20:50 & 8.8 & $1.70 \pm 0.51$ & $47.3 \pm 4.0$ \\
\hline
\end{tabular}


TABLE 4. Comparison of Bakersfield, CA lidar and $\mathrm{PM}_{2.5}$ data

\begin{tabular}{|c|c|c|c|c|c|c|c|}
\hline \multicolumn{4}{|c|}{2003 summer campaign } & \multicolumn{4}{|c|}{2007 winter campaign } \\
\hline Date & AOD & $\begin{array}{l}\text { PBL height } \\
(\mathrm{km})\end{array}$ & $\begin{array}{c}\mathrm{PM}_{2.5} \\
\left(\mu \mathrm{g} \mathrm{m}^{-3}\right)\end{array}$ & Date & AOD & $\begin{array}{l}\text { PBL height } \\
(\mathrm{km})\end{array}$ & $\begin{array}{c}\mathrm{PM}_{2.5} \\
\left(\mu \mathrm{g} \mathrm{m}^{-3}\right)\end{array}$ \\
\hline June 3 & 0.2472 & 1.63 & 19.5 & Feb. 15 & 0.1855 & 1.32 & 18.9 \\
\hline June 5 & 0.2423 & 1.57 & 21.9 & Feb. 16 & 0.2020 & 1.11 & 35.8 \\
\hline June 5 & 0.2579 & 1.81 & 17.0 & Feb. 16 & 0.2371 & 1.17 & 29.7 \\
\hline June 11 & 0.2244 & 1.24 & 9.0 & Feb. 17 & 0.0604 & 0.51 & 32.1 \\
\hline June 12 & 0.1696 & 1.54 & 18.5 & Feb. 17 & 0.0504 & 0.87 & 30.0 \\
\hline June 17 & 0.1145 & 1.47 & 13.5 & & & & \\
\hline Mean & 0.2093 & 1.54 & 16.6 & Mean & 0.1471 & 1.00 & 29.3 \\
\hline St. Dev. & 0.056 & 0.19 & 4.6 & St. Dev. & 0.086 & 0.32 & 6.3 \\
\hline
\end{tabular}


Table 5. Relationship between AOD, PBL, and $\mathrm{PM}_{2.5}$ in Bakersfield, CA

2003 summer campaign
$\mathrm{AOD} \mathrm{PBL}{ }^{-1} \pm \mathrm{SD}\left(\mathrm{km}^{-1}\right)$
$0.136 \pm 0.037$
$25.6 \pm 9.1$
$\mathrm{PM}_{2.5} \times \mathrm{PBL} \pm \mathrm{SD}\left(\mu \mathrm{g} \mathrm{m}^{-3} \mathrm{~km}\right)$
$0.140 \pm 0.057$
$29.2 \pm 9.1$

2007 winter campaign 
Table 6. Yearly comparison of MODIS AOD within the San Joaquin Valley (SJV)

\begin{tabular}{cccc}
\hline \hline & \multicolumn{2}{c}{ Mean AOD within SJV } & \% Difference \\
Year & Winter (February) & Summer (June) & \\
\hline 2003 & 0.0758 & 0.1620 & 72 \\
2004 & 0.0911 & 0.1146 & 23 \\
2005 & 0.1237 & 0.1438 & 15 \\
2006 & 0.1035 & 0.2130 & 69 \\
2007 & 0.1412 & 0.1154 & -20 \\
2008 & 0.1293 & 0.3087 & 82 \\
6-year & $\mathbf{0 . 1 1 5 0}$ & $\mathbf{0 . 1 7 8 3}$ & $\mathbf{4 3}$
\end{tabular}

The percent difference was calculated using the difference between the winter and summer AOD divided by the mean. 
Table 7. Yearly comparison of $\mathrm{PM}_{2.5}$ mass concentration in Bakersfield, CA

\begin{tabular}{cccc}
\hline \hline & Mean PM $_{2.5}$ from Bakersfield-5558 CA $\left(\mu \mathrm{g} / \mathrm{m}^{3}\right)$ & $\%$ Difference \\
Year & Winter (February) & Summer (June) & \\
\hline 2003 & 25 & 17 & 38 \\
2004 & 16 & 13 & 21 \\
2005 & 30 & 13 & 73 \\
2006 & 30 & 14 & 84 \\
2007 & 32 & 13 & 24 \\
2008 & 33 & 26 & $\mathbf{5 5}$ \\
6-year & $\mathbf{2 8}$ & $\mathbf{1 6}$ & \\
\hline
\end{tabular}

The percent difference was calculated using the difference between the winter and summer PM2.5 concentrations divided by the mean. 


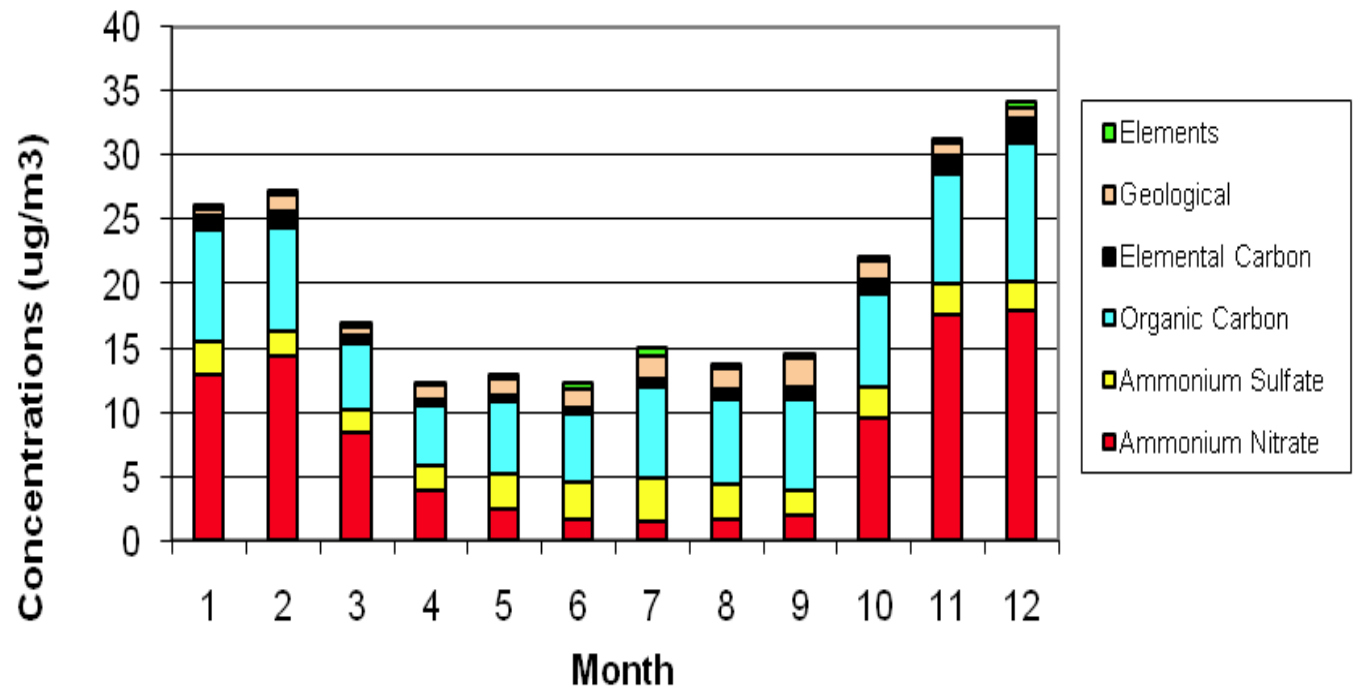

Fig. 1. Seasonal pattern and composition of $\mathrm{PM}_{2.5}$ near Bakersfield, CA from San Joaquin Valley Air Pollution Control District, 2008 PM$_{2.5}$ Plan - Final Adopted (2008b). 


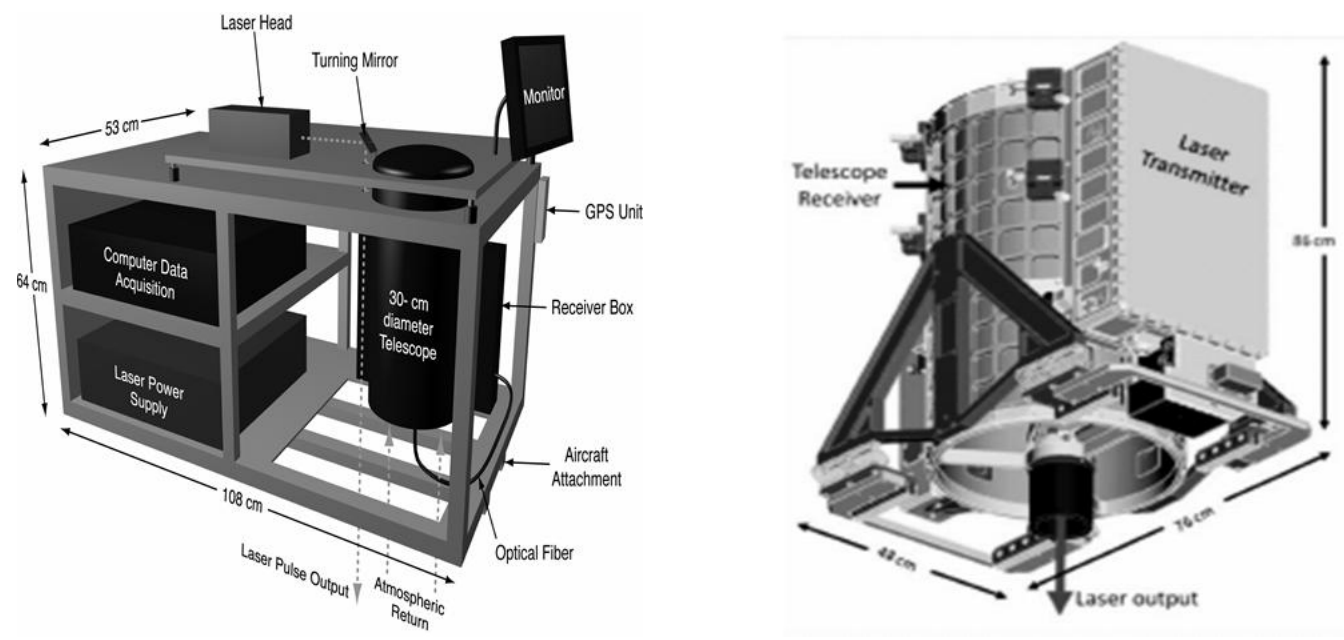

Figure 2. Left, compact aerosol lidar (CAL) system for aircraft deployment; and Right, airborne high spectral resolution lidar (HSRL) configured for aircraft deployment. 

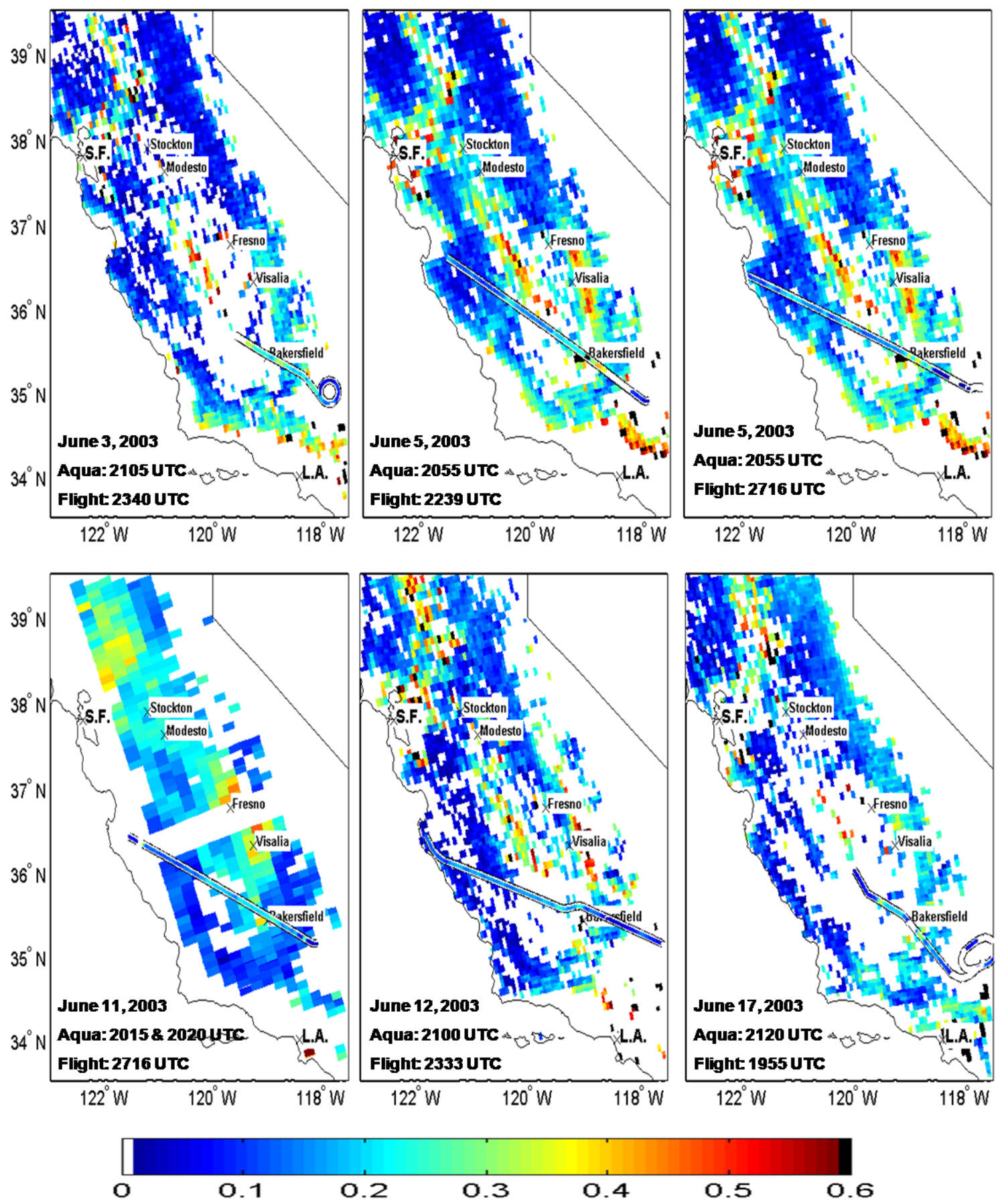

AOD

Figure 3. Summer 2003 comparison of MODIS (550-nm) 5x5-km AOD and flight tracks for CAL (converted 532-nm) AOD in the San Joaquin Valley, California. 

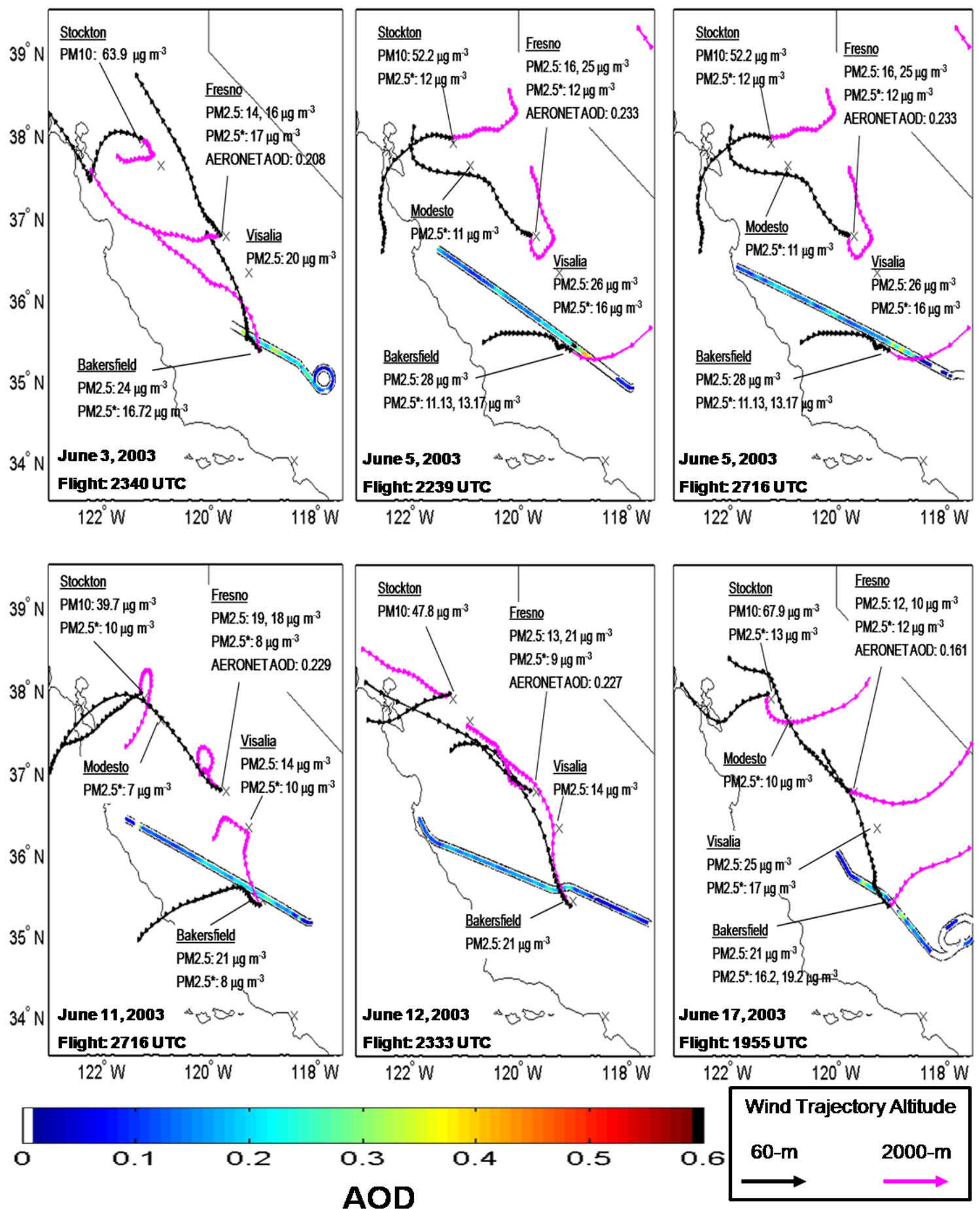

Figure 4. AOD of CAL flight track (converted 532-nm) with back trajectories (markers represent 1-hour time intervals) at different altitudes (shown in different colors), $\mathrm{PM}_{10}$ and $\mathrm{PM}_{2.5}$ mass concentrations at the time of the nearest MODIS overpass, and AERONET AOD (500-nm) measured at Fresno, CA during the summer 2003 San Joaquin Valley campaign. The PM2.5* denotes 24-hr averages. 

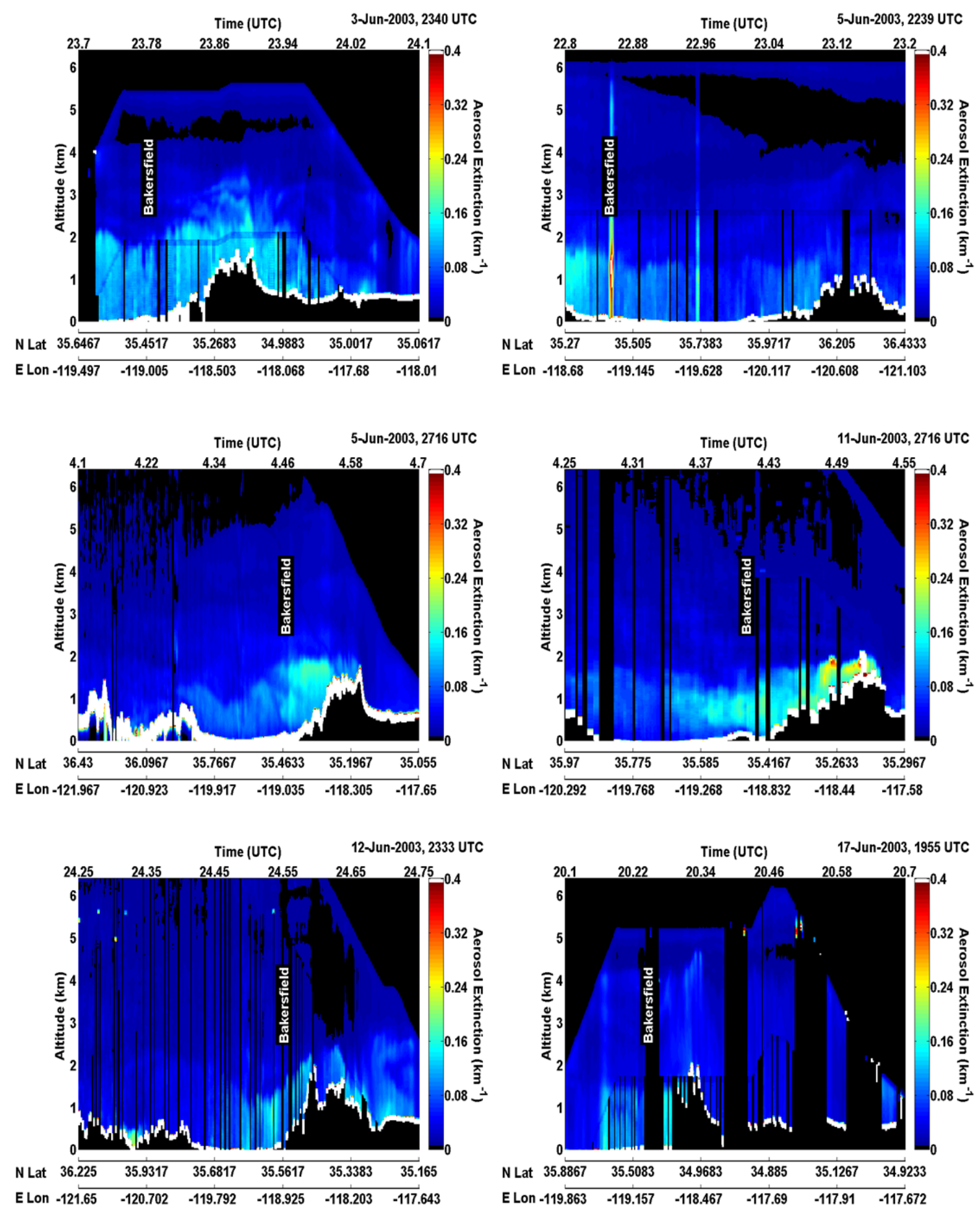

Figure 5. Curtain plots of the converted 532-nm lidar extinction during the summer 2003 San Joaquin Valley campaign. Bakersfield, CA is indicated in each plot. 

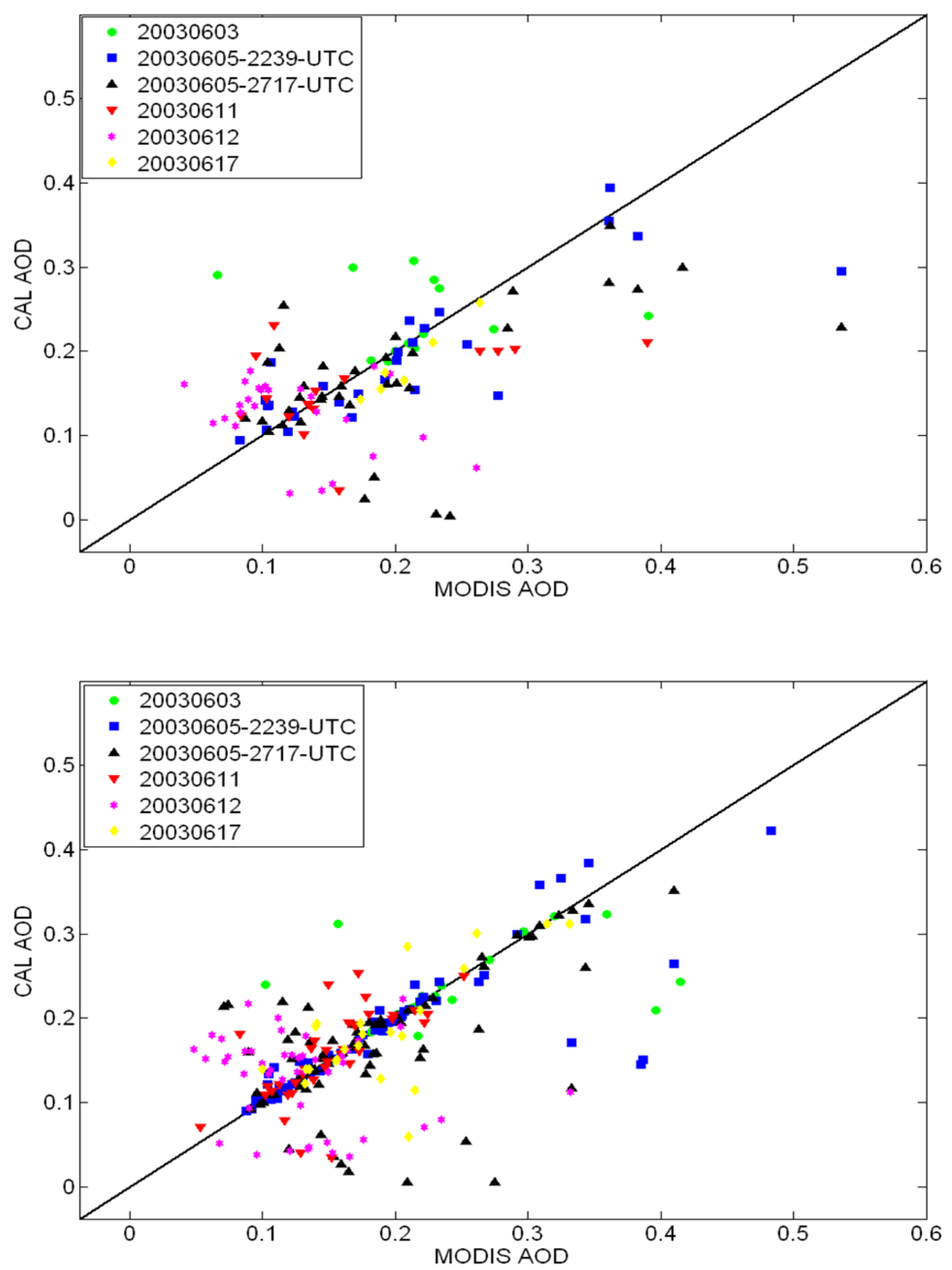

Figure 6. Comparison of MODIS and lidar-derived AOD from each summer 2003 flight for CAL at $10 \times 10-\mathrm{km}$ resolution (top panel, R-squared $=0.311$ ) and $5 \times 5-\mathrm{km}$ resolution (bottom panel, R-squared $=0.396$ ). 

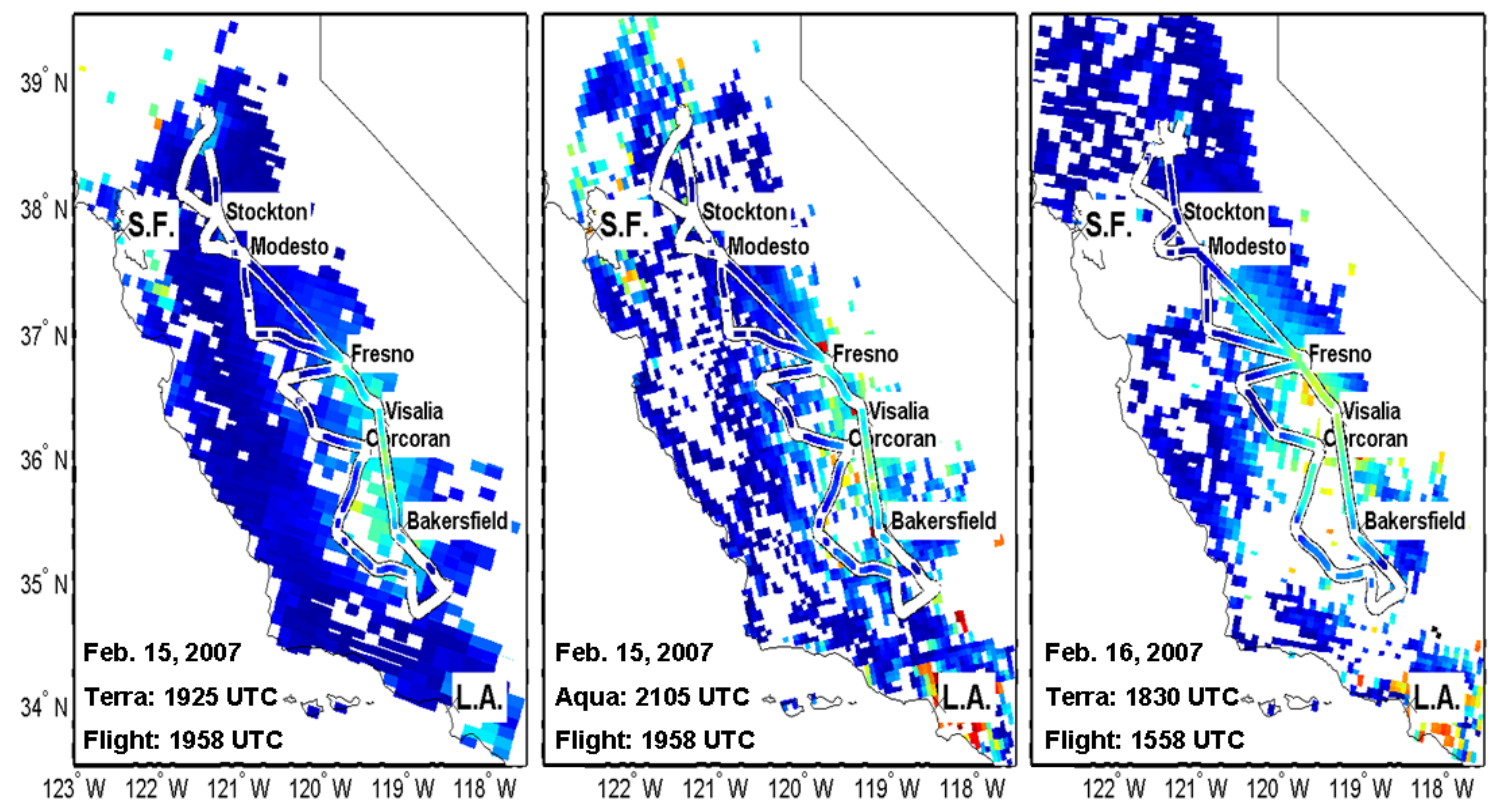

$122^{\circ} \mathrm{W} 121^{\circ} \mathrm{W} 120^{\circ} \mathrm{W} 119^{\circ} \mathrm{W} 118^{\circ} \mathrm{W}$

$122^{\circ} \mathrm{W} 121^{\circ} \mathrm{W} 120^{\circ} \mathrm{W} 119^{\circ} \mathrm{W} 118^{\circ} \mathrm{W}$
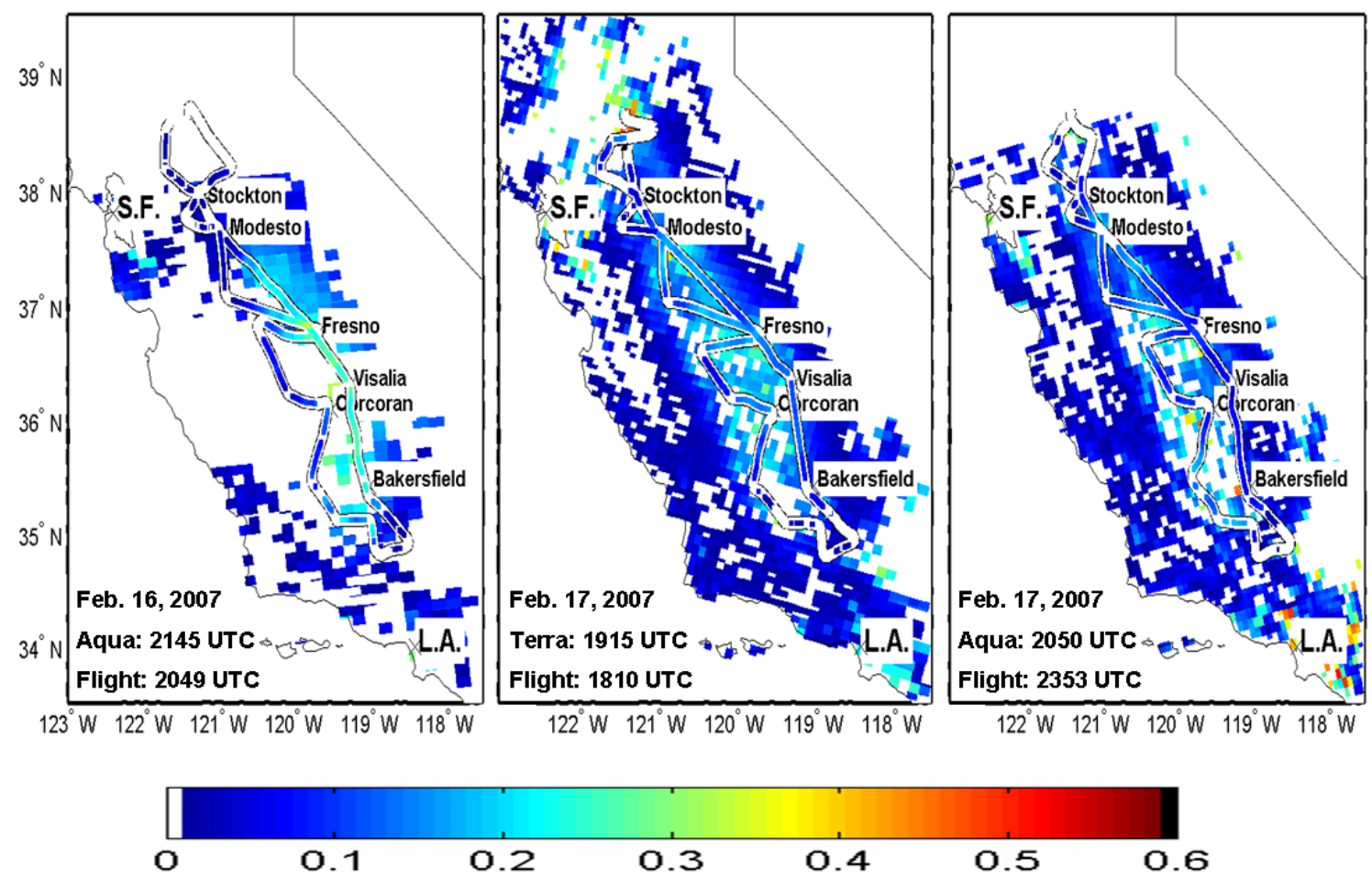

Figure 7. Winter 2007 comparison of MODIS (550-nm) 5x5-km AOD and flight tracks for HSRL (532-nm) AOD in the San Joaquin Valley, California. 

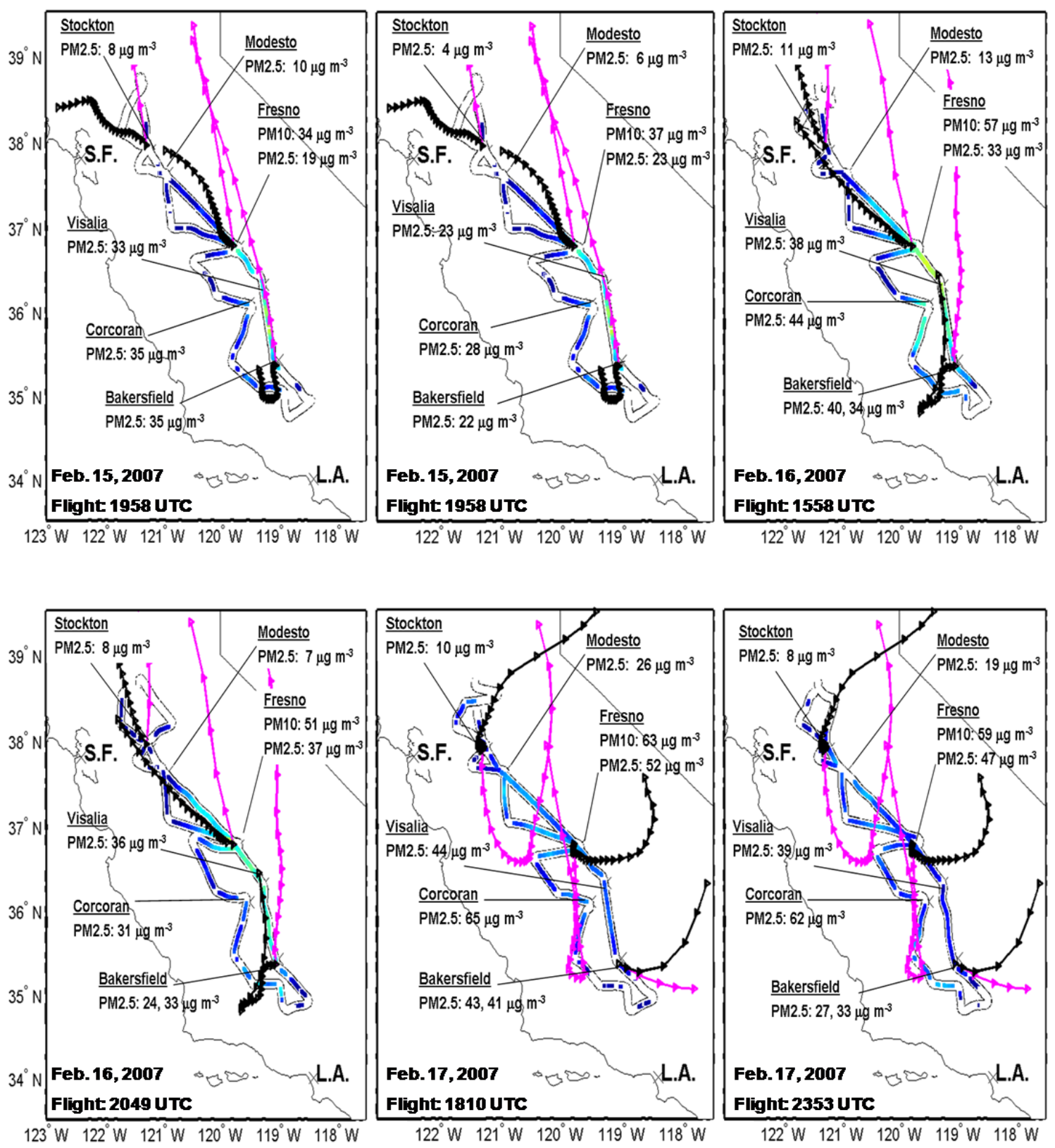

$122^{\circ} \mathrm{W} 121^{\circ} \mathrm{W} 120^{\circ} \mathrm{W} 119^{\circ} \mathrm{W} 118^{\circ} \mathrm{W}$

$122^{\circ} \mathrm{W} 121^{\circ} \mathrm{W} 120^{\circ} \mathrm{W} 119^{\circ} \mathrm{W} 118^{\circ} \mathrm{W}$

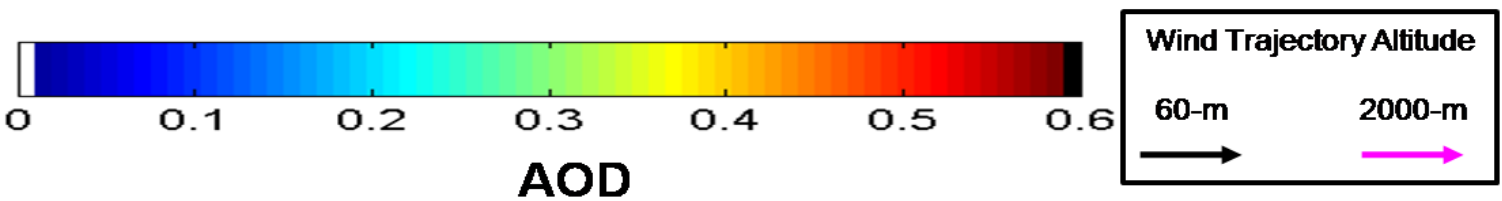

Figure 8. AOD of HSRL flight track (532-nm) with back trajectories (markers represent 1-hour time intervals) at different altitudes (shown in different colors), $\mathrm{PM}_{10}$ and $\mathrm{PM}_{2.5}$ mass concentrations at the time of the nearest MODIS overpass during the winter 2007 San Joaquin Valley campaign. 

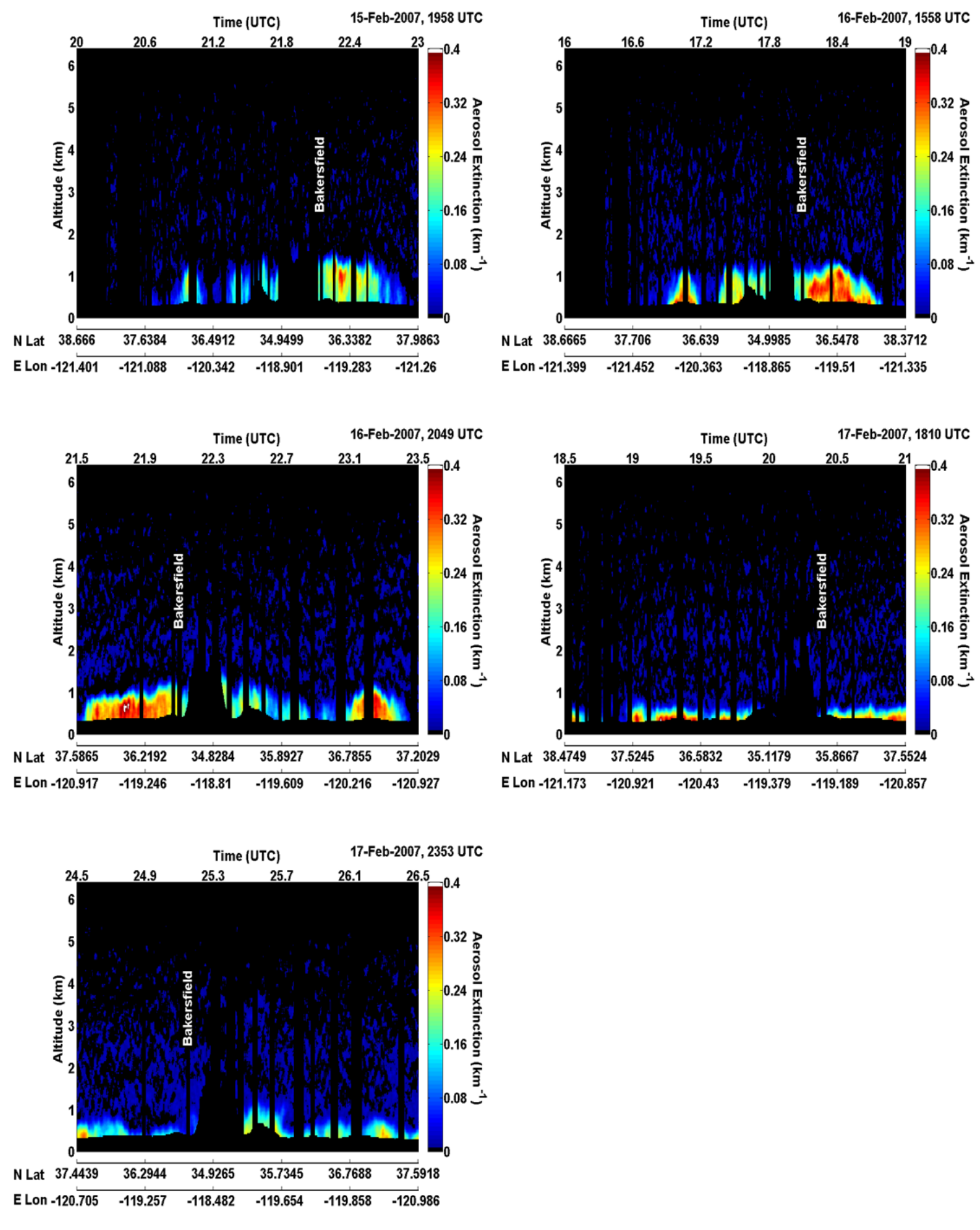

Figure 9. Curtain plots of the 532-nm lidar extinction during the winter 2007 San Joaquin Valley campaign. Bakersfield, CA is indicated in each plot. 

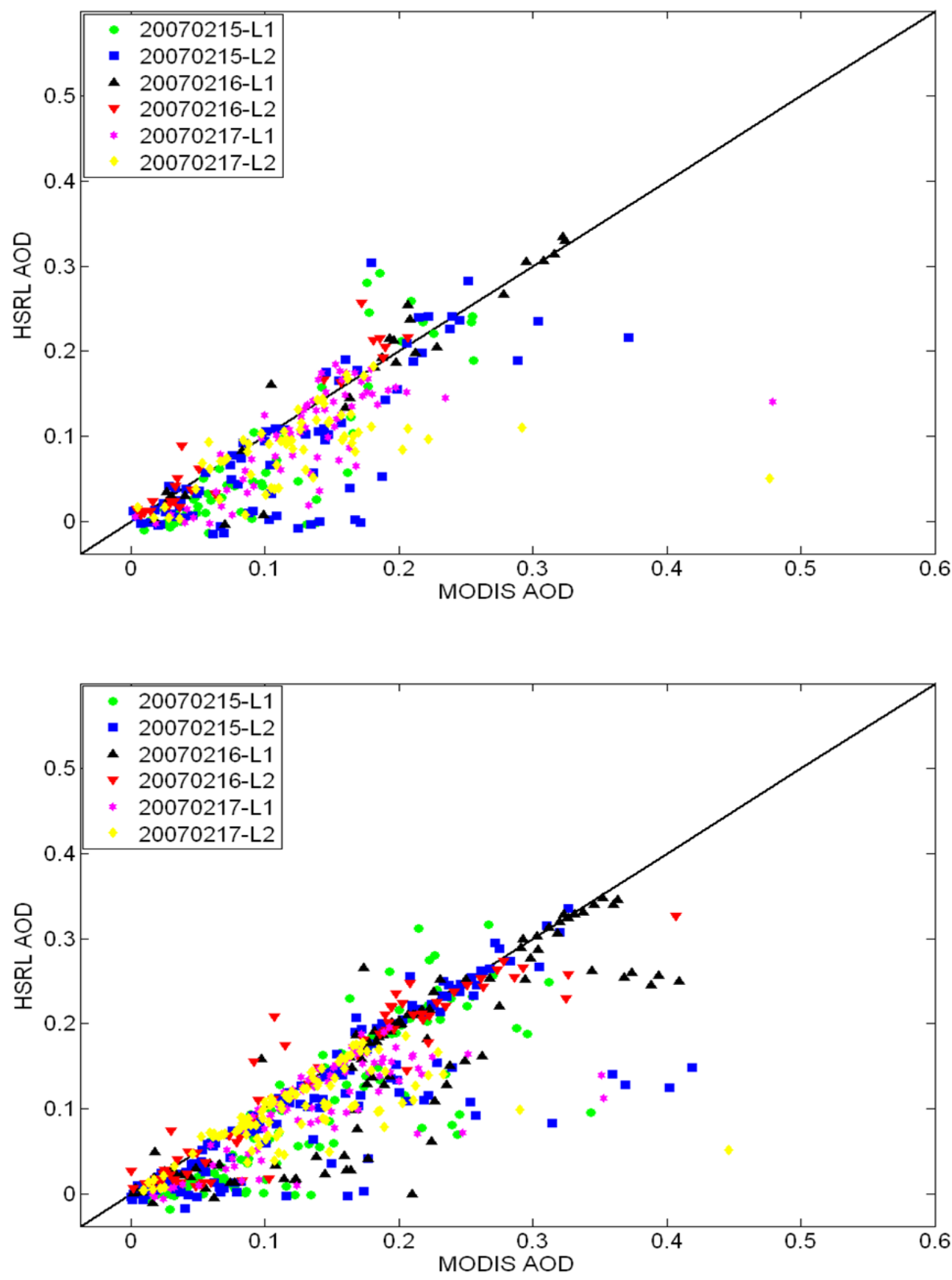

Figure 10. Comparison of MODIS and lidar-derived AOD from each winter 2007 flight for HSRL at $10 \times 10-\mathrm{km}$ resolution (top panel, R-squared $=0.539$ ) and $5 \times 5-\mathrm{km}$ resolution (bottom panel, R-squared $=0.696$ ). 


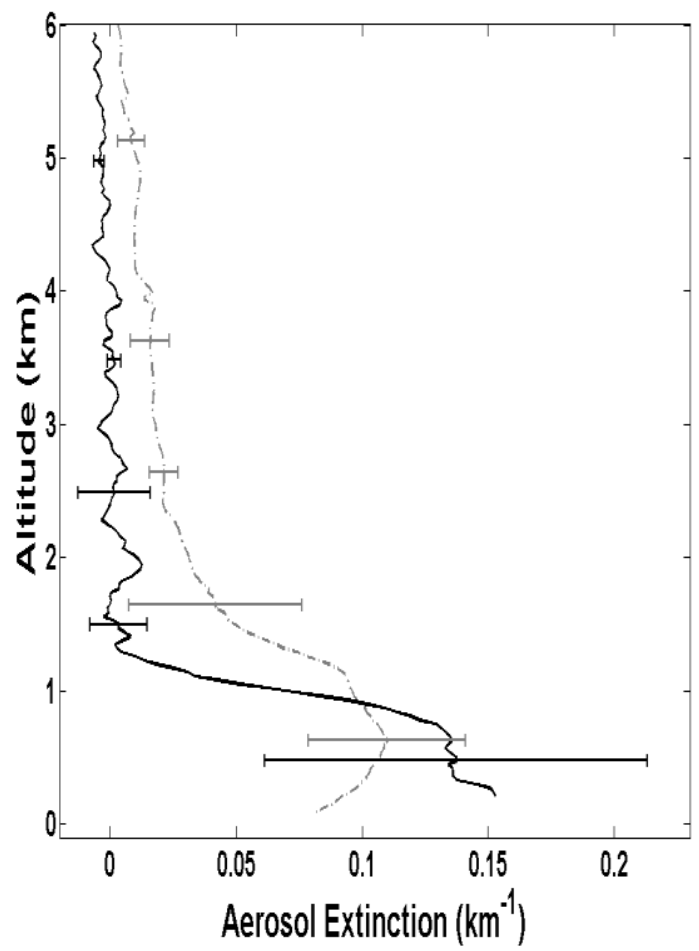

Figure 11. Comparison of mean 532-nm aerosol extinction profiles near Bakersfield, CA for summer 2003 campaign (dashed line) and 2007 winter campaign (solid line). 

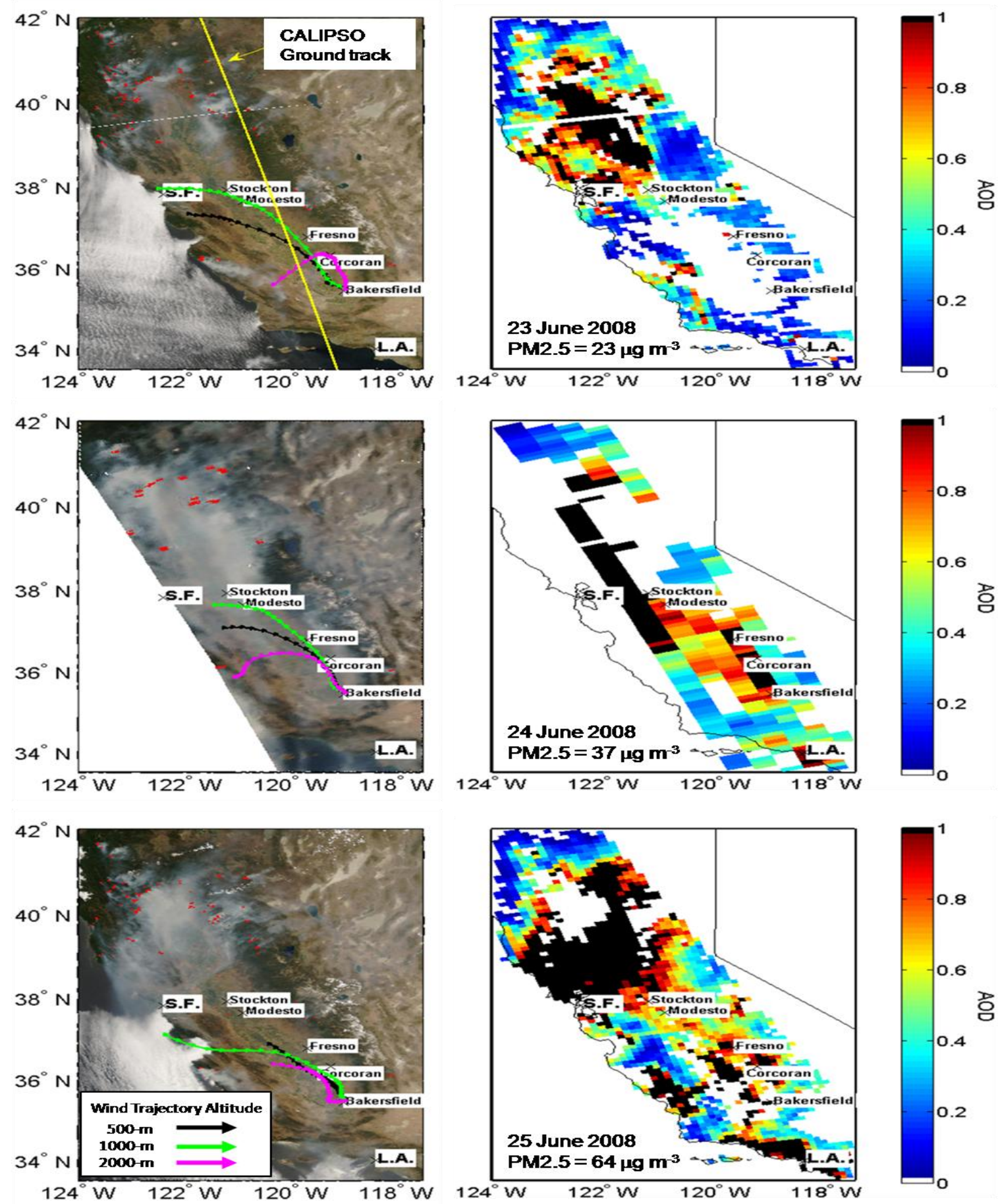

Figure 12. Smoke pollution from wildfires during the 2008 Lightning Siege. The MODIS True Color images along with HYSPLIT 24-hour back trajectories are shown in the left panels. The right panels show the MODIS AOD and the $\mathrm{PM}_{2.5}$ measured at Bakersfield, $\mathrm{CA}$ at the time of the overpass. There was a CALIPSO overpass of the Central Valley on 23 June 2008. 


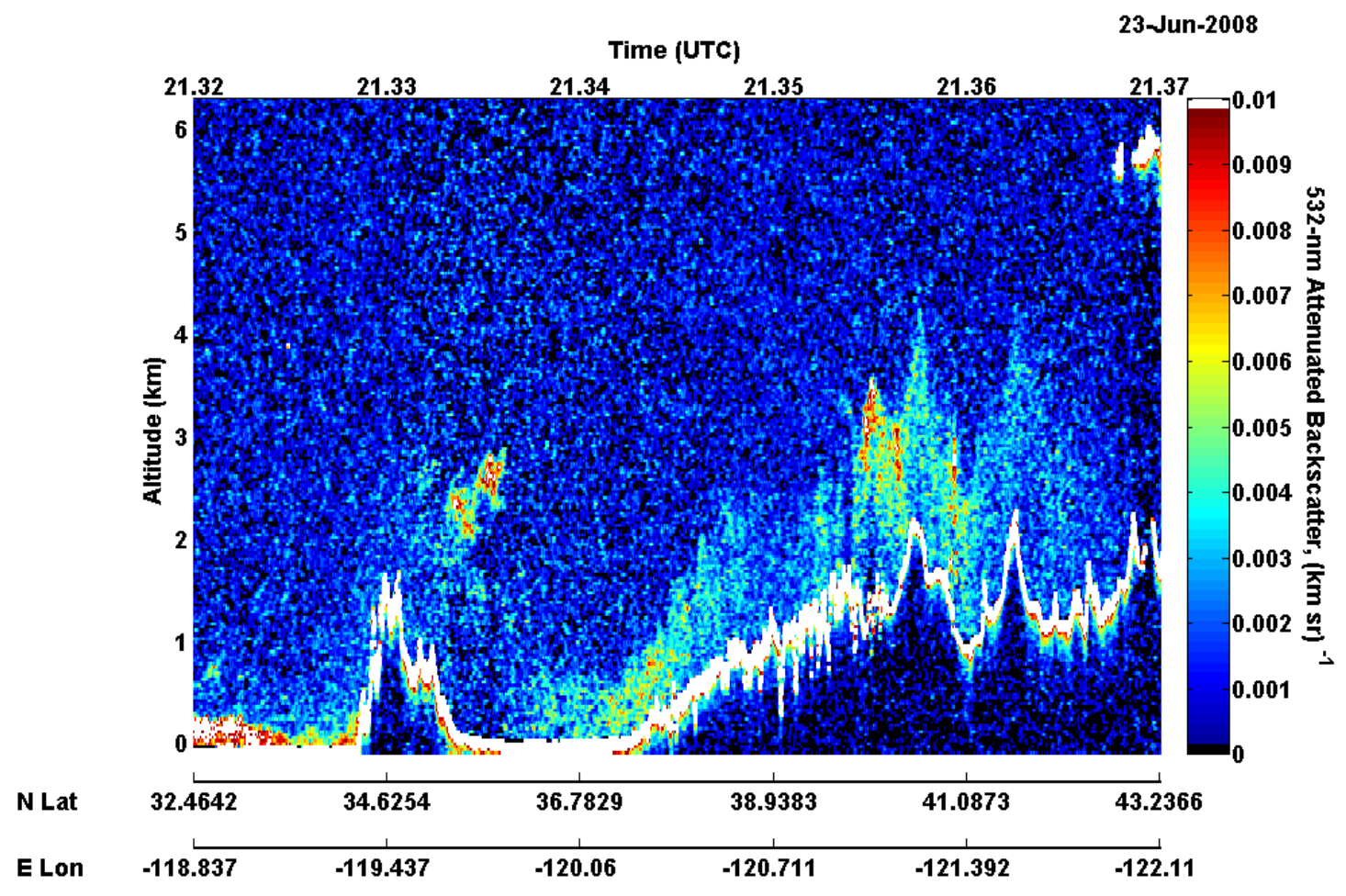

Figure 13. The aerosol backscattering coefficient measured by CALIPSO on 23 June 2008. Smoke layers aloft as high as 4-km are seen passing over the mountains. 